\title{
Ombre e fiori
}

S. Marengo

\section{Ombra di donna}

Perché mai donna non posso allontanare il pensiero che turba e che è per te. Forse, lo pensi anche tu, il sublime appartiene al paradiso e il nostro è stato breve. Vedo un'ombra che si muove, più vicina e poi passa. Non mi tuffo nella sera; la tua ombra, scomparsa.

\section{I fiori del mare}

Dal cuore della grande onda, precipitando, nascono i fiori del mare, carnosi, a tutta corolla, con petali uguali e gonfi. Ammucchiati a milioni, fanno riccioli a battelli e remi e nessuno mai ne ha già colti.

Tra cento anni nasceranno ancora dietro le navi e moriranno, nel tempo di uno sguardo breve, prima d'ogni altro fiore.

\section{I chiaroscuri}

Ombre e luci, sfumate, seguono ovunque, a notte, la luna: son chiaroscuri ... Instancabili, prendono e mollano il buio a rimpiattino, sino a che sole, luna o cos'altro non smetteranno di giocare anche loro. E soporosamente gli uomini ronfano.

\section{Senz'ombra un fiore}

Il nostro incontro rimane ancora una sublime tua fotografia.

La luce cresceva dal mare, arbusti odoravano intorno. Scambiavamo parole, voci di coro dalla grande dolcezza per noi figli del sole. Giovane donna, dagli occhi azzurri e grigi, vorrei lasciarti senz'ombra un fiore. 